\title{
Study on the biomechanical responses of the loaded bone in macroscale and mesoscale by multiscale poroelastic FE analysis
}

\author{
WeiLun Yu ${ }^{1}$, XiaoGang Wu ${ }^{1 *}$, HaiPeng Cen ${ }^{2}$, Yuan Guo ${ }^{1}$, ChaoXin Li $^{1}$, YanQin Wang ${ }^{1}$, YiXian Qin ${ }^{3}$ \\ and WeiYi Chen ${ }^{*}$
}

*Correspondence:
Xiaogangwutyut@163.com;
chenweiyi211@163.com
${ }^{1}$ College of Biomedical
Engineering, Shanxi Key Lab.
of Material Strength, College
of Biomedical Engineering
\& Structural Impact, Taiyuan
University of Technology,
Taiyuan 030024, Shanxi,
China
Full list of author information
is available at the end of the
article
adaptation, distribution and reproduction in any medium or format, as long as you give appropriate credit to the original author(s) and the source, provide a link to the Creative Commons licence, and indicate if changes were made. The images or other third party material in this article are included in the article's Creative Commons licence, unless indicated otherwise in a credit line to the material. If material is not included in the article's Creative Commons licence and your intended use is not permitted by statutory regulation or exceeds the permitted use, you will need to obtain permission directly from the copyright holder. To view a copy of this licence, visit http://creativecommons.org/ licenses/by/4.0/. The Creative Commons Public Domain Dedication waiver (http://creativecommons.org/publicdomain/zero/1.0/) applies to the data made available in this article, unless otherwise stated in a credit line to the data. 
suggested method is expected to provide dependable biological information for better understanding the bone mechanotransduction and signal transduction.

Keywords: Mechanotransduction, Multiscale, Finite element model, Poroelastic, Biomechanical responses

\section{Background}

Bone has composite hierarchical structures to achieve diverse mechanical, biological, and chemical functions, such as support and protection, transport, storage cells, and mineral ion homeostasis [1]. The properties of bone are mainly due to its specific hierarchical structure and composition, affording bone characteristics of rigidity, strength, permeability, porosity, toughness, and flexibility, and they can keep close communication and coordination with each other to achieve unified macroscopic functions [1,2]. The stress and strain distribution and fluid flow in bone play an important role in the effective realization of various functions of bone. Bone structure mainly includes geometry structure, micro-architecture, and material composition. From the scale point of view, it is composed of macroscopic bone tissues, mesoscopic Haversian systems, microscopic lacuna-canalicular system, and nanoscopic collagen fibers and elementary constituents. From the compositional point of view,it is composed of solid phase (type-I collagen and hydroxyapatite crystals) and fluid phase (water and other organic fluids [3]. According to Wolff's law, bone strength is determined by its structure, and bone structure is regulated by external mechanical stimuli and intelligently adapt to mechanical environment so as to bear the load in the optimum structural form and to obtain the maximum structural strength with the least structural material [4].Within the bone tissue, mechanical stress and bone structure keep a balance relationship that defined the activity of osteoblasts and osteoclasts, and there is a threshold for mechanical stress [5]. Osteoblasts are more active if mechanical stress beyond the maximum threshold, or osteoclasts are more active if the mechanical stress below the minimum threshold [4-7]. Therefore, the distribution of stress and strain in bone affects the bone microstructure and the activity of bone cells. Fluid flow in osteons can produce a series of effect, such as fluid shear stress, pore pressure gradient, solute transport, and streaming potential, and some of these effects can be sensed by osteocytes as signals to trigger bone formation and bone resorption to adapt the continuous change of the mechanical environment [8]. The bone will produce deformation which induced fluid flow in bone under physiological loading, and osteocytes are sensitive to fluid flow and its induced effects [9]. It is significant to research the stress and strain field and the behaviors of fluid flow in different scales of bone under physiological load.

Multiscale model of bone can alternative material parameter of any hierarchical level to determine its effect on bone properties, such as porosity, elastic modulus [3], and permeability [10]. A scaffold composed of materials with multiscale porosity can be used to direct bone regeneration and morphology by controlling the hierarchical structure of the scaffold [11]. Macro-, meso-, and microscale of femoral model were constructed, and the strain amplification factor was found at the lacuna [12]. Pastrama et al. analyzed the influence of pore pressure on bone remodeling, and the pore pressure was caused by the physiological load and transferred from macroscale to microscale [13]. However, a sensitivity analysis of the poroelastic properties of hierarchical structure of bone and 
a detailed study on the propagation of physiological loading and fluid flow across the length scales of different functional units has not been made yet.

The objective of this research was to develop a multiscale model that included various functional units at each hierarchical level to evaluate the response of poroelastic behaviors under axial compressive cyclic loading. FE analysis is performed three times, at macroscale, macro-mesoscale, and mesoscale structural levels (Fig. 1, Tables 1, 2, 3 and 4), with each analysis at a greater level of refinement, using COMSOL Multiphysics software. This model neglected the bone marrow cavity and trabeculae, only considers the tissue from the endosteum to periosteum, and the mechanical property and the flowing discipline of various functional units was observed. At the mesoscale, an osteon which cut from the whole model was refined, and the effects of $E$ and $k_{\text {lcp }}$ on the fluid flow and stress and strain field were investigated. All properties and parameters were based on literature reports, and the solid structure and interstitial fluid were assumed as transverse isotropic poroelastic material and compressible liquid, respectively. This paper provides a deeper understanding of the mechanotransduction and stimulation by fluid flow which induces bone remodeling and bone metabolism.

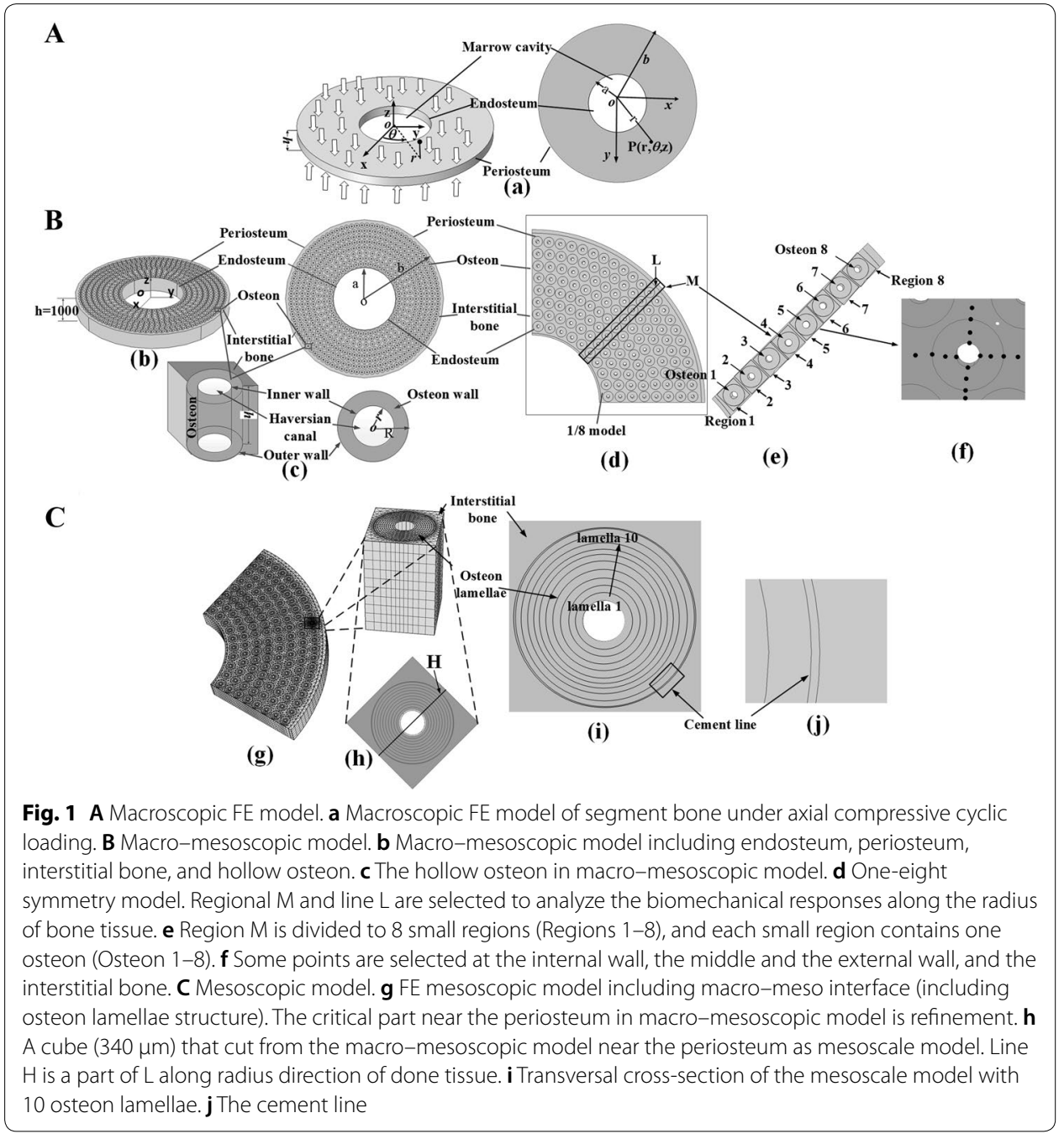


Table 1 Material constants used in macroscale model

\begin{tabular}{lll}
\hline Parameter & Description & Value \\
\hline$E_{r}$ & Radial drained Young's modulus & $14.58(\mathrm{GPa})$ \\
$V_{r}$ & Radial drained Poisson's ratio & 0.325 \\
$E_{z}$ & Axial drained Young's modulus & $20.3(\mathrm{GPa})$ \\
$V_{z}$ & Axial drained Poisson's ratio & 0.25 \\
$\mathrm{M}$ & Biot's modulus & $38(\mathrm{GPa})$ \\
$\mathrm{a}$ & Biot's effective coefficient & 0.12 \\
$\varphi_{v}$ & Vascular porosity & 0.04 \\
$\rho_{\mathrm{S}}$ & Solid density & $2000\left(\mathrm{~kg} / \mathrm{m}^{3}\right)$ \\
$\rho_{\mathrm{f}}$ & Fluid density & $1000\left(\mathrm{~kg} / \mathrm{m}^{3}\right)$ \\
$k_{\mathrm{vp}}$ & Vascular permeability & $10^{-15}\left(\mathrm{~m}^{2}\right)$ \\
$\mu$ & Dynamic viscosity & $10^{-3}(\mathrm{~Pa} \mathrm{~s})$ \\
$\mathrm{a}$ & Inner radius of bone tissue & $2(\mathrm{~mm})$ \\
$\mathrm{b}$ & Outer radius of bone tissue & $5(\mathrm{~mm})$ \\
$C_{p}$ & Fluid compressibility & $4 \times 10^{-10}(1 / \mathrm{Pa})$ \\
\hline
\end{tabular}

Table 2 Material parameters used in the macro-mesoscopic FE model

\begin{tabular}{lllll}
\hline & Osteon & Interstitial bone & Endosteum & Periosteum \\
\hline$E_{r}$ & $15.75(\mathrm{GPa})$ & $17.325(\mathrm{GPa})$ & $4.41(\mathrm{MPa})$ & $4.41(\mathrm{MPa})$ \\
$v_{r}$ & 0.328 & 0.2925 & 0.49 & 0.49 \\
$E_{z}$ & $20.3(\mathrm{GPa})$ & $22.33(\mathrm{GPa})$ & $25.67(\mathrm{MPa})$ & $25.67(\mathrm{MPa})$ \\
$v_{r}$ & 0.25 & 0.225 & 0.49 & 0.49 \\
$k_{\text {lcp }}$ & $10^{-19} \mathrm{~m}^{2}$ & $10^{-19} \mathrm{~m}^{2}$ & $2.7 \times 10^{-16} \mathrm{~m}^{2}$ & $2.7 \times 10^{-16} \mathrm{~m}^{2}$ \\
\hline
\end{tabular}

Table 3 Settings of osteon lamella $E$ for poroelastic analysis (GPa)

\begin{tabular}{clllll}
\hline Case 1 & $E_{r} 1, E_{z} 1$ & $E_{r} 2, E_{z} 2$ & $E_{r} 3, E_{z} 3$ & $E_{r} 4, E_{z} 4$ & $E_{r} 5, E_{z} 5$ \\
& $11,14.3$ & $12,15.6$ & $13,16.9$ & $14,18.2$ & $15,19.5$ \\
& $E_{r} 6, E_{z} 6$ & $E_{r} 7, E_{z} 7$ & $E_{r} 8, E_{z} 8$ & $E_{r} 9, E_{z} 9$ & $E_{r} 10, E_{z} 10$ \\
Case 2 & $17,22.1$ & $18,23.4$ & $19,24.7$ & 20,26 \\
& $16,20.8$ & $E_{r} 2, E_{z} 2$ & $E_{r} 3, E_{z} 3$ & $E_{r} 4, E_{z} 4$ & $E_{r} 5, E_{z} 5$ \\
& $E_{r} 1, E_{z} 1$ & $18,23.4$ & $17,22.1$ & $16,20.8$ \\
& 20,26 & $19,24.7$ & $E_{r} 8, E_{z} 8$ & $E_{r} 9, E_{z} 9$ & $E_{r} 10, E_{z} 10$ \\
& $E_{r} 6, E_{z} 6$ & $E_{r} 7, E_{z} 7$ & $13,16.9$ & $12,15.6$ & $11,14.3$ \\
& $15,19.5$ & $14,18.2$ & $E_{r} 3, E_{z} 3$ & $E_{r} 4, E_{z} 4$ & $E_{r} 5, E_{z} 5$ \\
& $E_{r} 1, E_{z} 1$ & $E_{r} 2, E_{z} 2$ & $16,20.8$ & $14,18.2$ & $12,15.6$ \\
& 20,26 & $18,23.4$ & $E_{r} 8, E_{z} 8$ & $E_{r} 9, E_{z} 9$ & $E_{r} 10, E_{z} 10$ \\
& $E_{r} 6, E_{z} 6$ & $E_{r} 7, E_{z} 7$ & $16,20.8$ & $18,23.4$ & 20,26 \\
\hline
\end{tabular}

\section{Results}

\section{Comparison of finite element method and numerical simulation}

The comparison of FP and FV along the radial direction of macroscale model (Fig. 1A) was shown in Fig. 2, and the computed results of the macroscale FE model showed good agreement with the results of numerical simulation, and the result error was acceptable, which verified the validity of the model. 
Table 4 Settings of osteon lamella permeability $\left(k_{\text {Icp }}\right)$ for poroelastic analysis $\left(\mathrm{m}^{2}\right)$

\begin{tabular}{|c|c|c|c|c|c|}
\hline \multirow[t]{4}{*}{ Case 4} & $k_{\text {lcp }} 1$ & $k_{\mathrm{lcp}}{ }^{2}$ & $k_{\mathrm{lcp}} 3$ & $k_{\text {lcp }} 4$ & $k_{\mathrm{lcp}} 5$ \\
\hline & $23 \times 10^{-19}$ & $21 \times 10^{-19}$ & $19 \times 10^{-19}$ & $17 \times 10^{-19}$ & $15 \times 10^{-19}$ \\
\hline & $k_{\mathrm{lcp}} 6$ & $k_{\mathrm{lcp}} 7$ & $k_{\mathrm{lcp}} 8$ & $k_{\mathrm{lcp}} 9$ & $k_{\mathrm{lcp}} 10$ \\
\hline & $13 \times 10^{-19}$ & $11 \times 10^{-19}$ & $9 \times 10^{-19}$ & $7 \times 10^{-19}$ & $5 \times 10^{-19}$ \\
\hline \multirow[t]{4}{*}{ Case 5} & $E_{r} 1, E_{z} 1$ & $E_{r} 2, E_{z} 2$ & $E_{r} 3, E_{z} 3$ & $E_{r} 4, E_{z} 4$ & $E_{r} 5, E_{2} 5$ \\
\hline & $5 \times 10^{-19}$ & $7 \times 10^{-19}$ & $9 \times 10^{-19}$ & $11 \times 10^{-19}$ & $13 \times 10^{-19}$ \\
\hline & $k_{\text {lcp }} 6$ & $k_{\mathrm{lcp}} 7$ & $k_{\mathrm{lcp}} 8$ & $k_{\mathrm{lcp}} 9$ & $k_{\mathrm{lcp}} 10$ \\
\hline & $15 \times 10^{-19}$ & $17 \times 10^{-19}$ & $19 \times 10^{-19}$ & $21 \times 10^{-19}$ & $23 \times 10^{-19}$ \\
\hline \multirow[t]{4}{*}{ Case 6} & $k_{\mathrm{lcp}} 1$ & $k_{\mathrm{lcp}}{ }^{2}$ & $k_{\mathrm{lcp}} 3$ & $k_{\mathrm{lcp}} 4$ & $k_{\mathrm{lcp}} 5$ \\
\hline & $23 \times 10^{-19}$ & $21 \times 10^{-19}$ & $19 \times 10^{-19}$ & $17 \times 10^{-19}$ & $15 \times 10^{-19}$ \\
\hline & $k_{\mathrm{lcp}} 6$ & $k_{\mathrm{lcp}} 7$ & $k_{\mathrm{lcp}} 8$ & $k_{\mathrm{lcp}} 9$ & $k_{\mathrm{lcp}} 10$ \\
\hline & $15 \times 10^{-19}$ & $17 \times 10^{-19}$ & $19 \times 10^{-19}$ & $21 \times 10^{-19}$ & $23 \times 10^{-19}$ \\
\hline
\end{tabular}
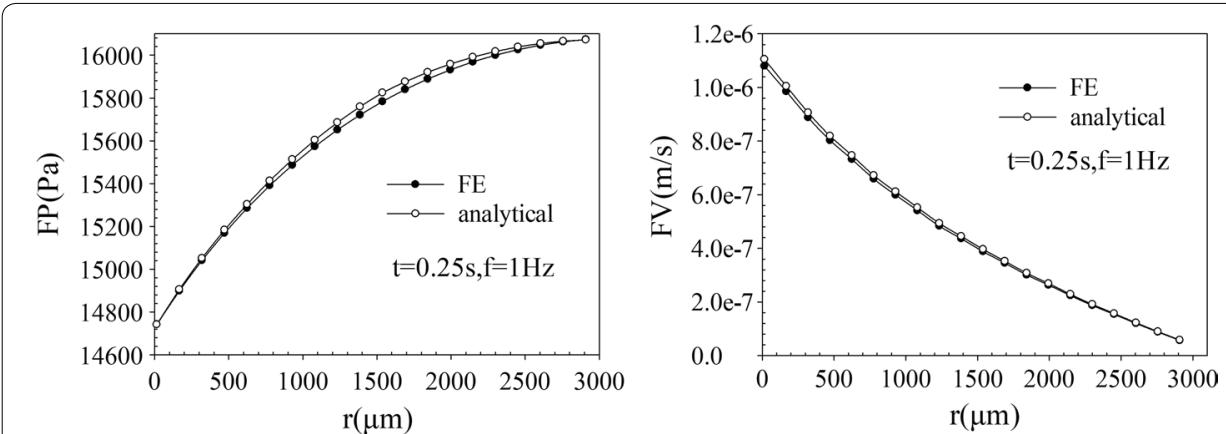

Fig. 2 Comparison of the analytical data and FE data of bone model at $t=0.25 \mathrm{~s}$. Fluid pressure FP (left) and velocity FV (right) vs bone radius

\section{The analyses of macro-mesoscopic FE model}

Because of the symmetry of geometric structure (Fig. 1B, C), in order to reduce the computation, 1/8 model was established (Fig. 1d). A region $M$ was taken along the radius of the bone tissue (Fig. 1d), and some points were get at different positions of the endosteum, interstitial bone, osteon, and periosteum within the region $\mathrm{M}$. The mean values of VMS (Fig. 3A, B), MPS (Fig. 3C), FP (Fig. 3D, E), and FV (Fig. 3F) with the loading time at these points were calculated, and we found that the VMS and MPS reached maximum values at around $t=0.5 \mathrm{~s}$, and the FP and FV reached maximum values at around $t=0.25 \mathrm{~s}$. At $t=0.5 \mathrm{~s}$, average VMS ( \pm standard deviation) from endosteum, osteon, interstitial bone, and periosteum regions was about $6.89 \times 10^{6} \pm 3.81 \times 10^{6} \mathrm{~Pa}, 2.04 \times 10^{7} \pm 5.27 \times 10^{5} \mathrm{~Pa}$, $2.04 \times 10^{7} \pm 2.80 \times 10^{6} \mathrm{~Pa}$, and $6.20 \times 10^{6} \pm 3.44 \times 10^{6} \mathrm{~Pa}$, respectively, and average MPS was about $7.56 \times 10^{-4} \pm 7.99 \times 10^{-5}, 2.69 \times 10^{-4} \pm 2.72 \times 10^{-6}, 2.5 \times 10^{-4} \pm 7.17 \times 10^{-5}$, and $6.65 \times 10^{-4} \pm 9.83 \times 10^{-5}$, respectively. At $t=0.25 \mathrm{~s}$, average FP was about $14,789 \pm 3 \mathrm{~Pa}, 32,241 \pm 10,700 \mathrm{~Pa}, 42,538 \pm 14,533 \mathrm{~Pa}$, and $5263 \pm 2.24 \mathrm{~Pa}$, respectively, and average FV was about $4.05 \times 10^{-8} \pm 8.4 \times 10^{-9} \mathrm{~m} / \mathrm{s}, 3.45 \times 10^{-8} \pm 1.91 \times 10^{-8} \mathrm{~m} / \mathrm{s}$, $1.12 \times 10^{-8} \pm 6.58 \times 10^{-9} \mathrm{~m} / \mathrm{s}$, and $1.72 \times 10^{-8} \pm 1.14 \times 10^{-8} \mathrm{~m} / \mathrm{s}$. It was worth noting that the FV was the absolute value of velocity.

The distributions of the maximum response of VMS, MPS, FP, and FV were shown in Fig. 4. The maximum VMS at interstitial bone was $2.24 \times 10^{7} \mathrm{~Pa}$, which was 


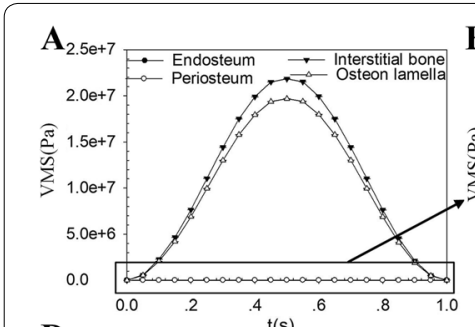

D
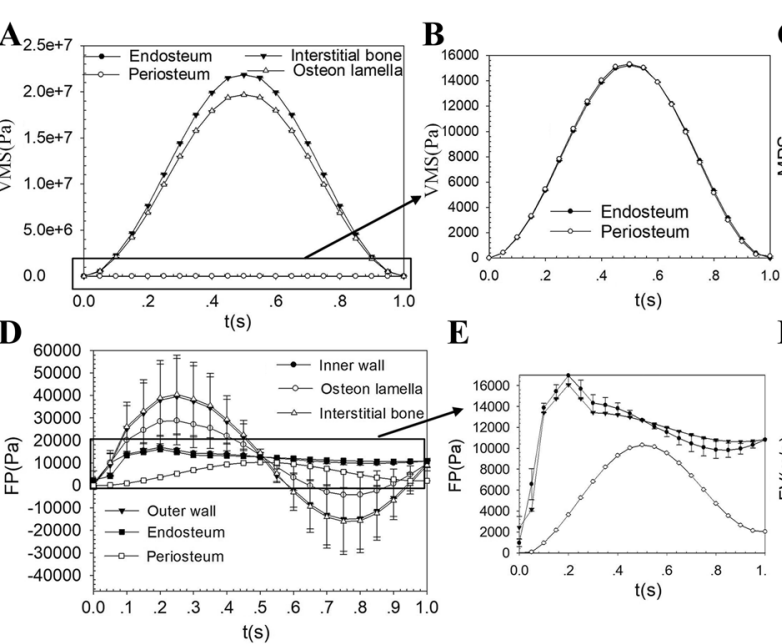

$\mathbf{E}$

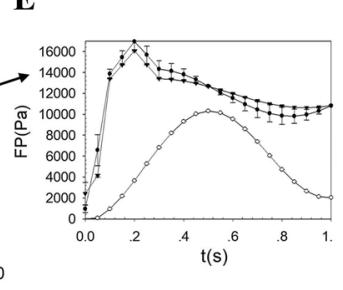

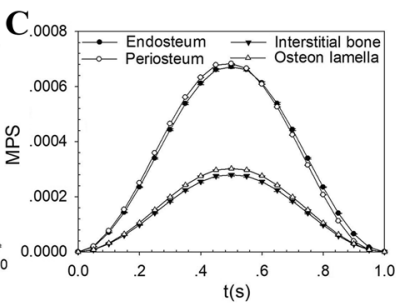

F

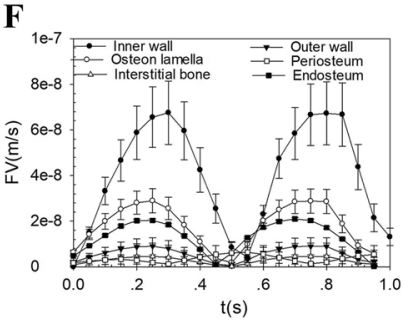

Fig. 3 Detailed analyses of the biomechanical responses of selected locations in Fig. If versus loading time. A The mean VMS of different locations versus time. B The enlarged region of part of $(\mathbf{A})$. C The mean MPS of different locations versus time. D The mean FP of different locations versus time. $\mathbf{E}$ The enlarged region of part of (D). F The mean FV of different locations versus time

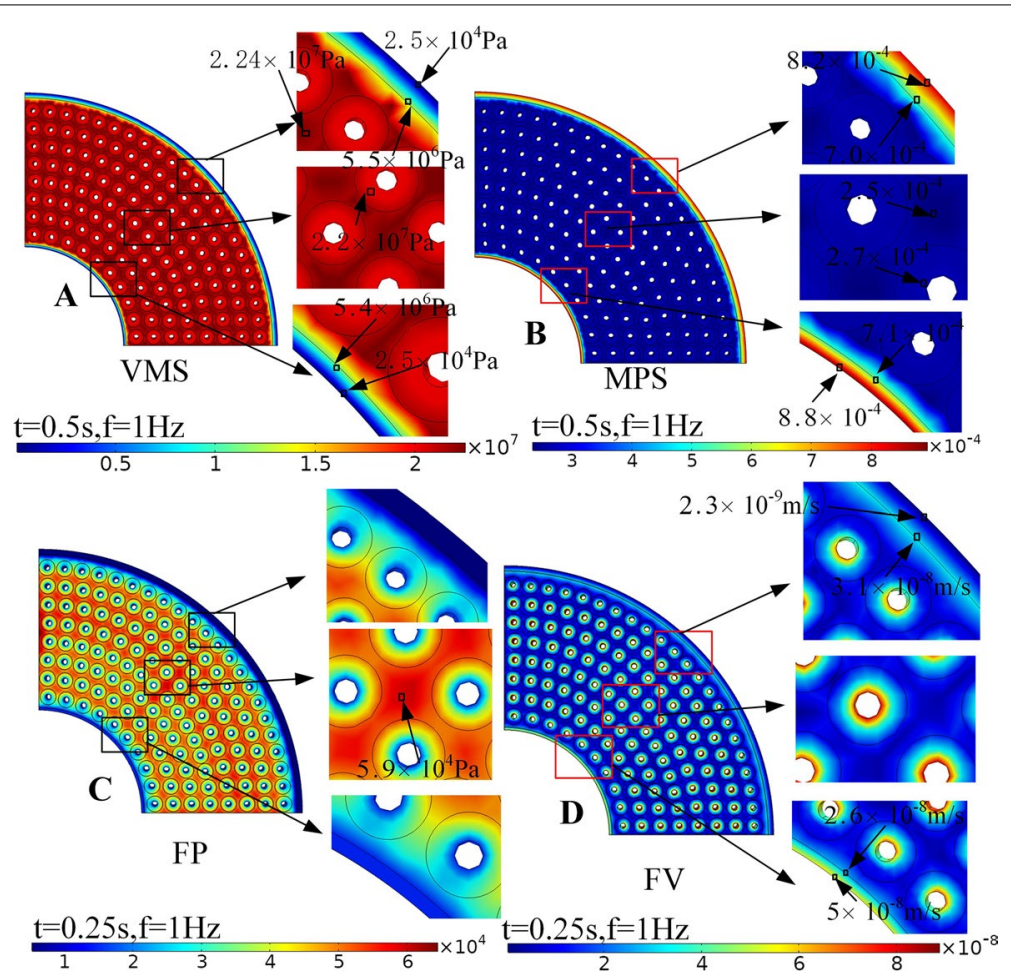

Fig. 4 The distributions of VMS (A), MPS (B), FP (C), and FV (D) under axial compressive cyclic loading

generally higher than that in other locations (Fig. 4A). The maximum VMS at periosteum $\left(5.5 \times 10^{6} \mathrm{~Pa}\right)$ and endosteum $\left(2.5 \times 10^{5} \mathrm{~Pa}\right)$ had minimum values among all functional units (Fig. 4A), while the maximum MPS $\left(8.4 \times 10^{-4}\right.$ and $\left.8.8 \times 10^{-4}\right)$ was 
significantly higher than other locations (Fig. 4B). The maximum FP around the endosteum $(14,786 \mathrm{~Pa})$ and periosteum (5264 $\mathrm{Pa}$ ) was significantly lower than other locations (Fig. 4C). In the same small region of bone tissue, the maximum FP of interstitial bone $\left(5.9 \times 10^{4} \mathrm{~Pa}\right)$ was greater than osteon $\left(4.8 \times 10^{4} \mathrm{~Pa}\right)(\mathrm{Fig} .4 \mathrm{C})$, but the FV of interstitial tissue $\left(1 \times 10^{-8} \mathrm{~m} / \mathrm{s}\right)$ was less than osteon $\left(8 \times 10^{-8} \mathrm{~m} / \mathrm{s}\right)$ (Fig. 4D). The $\mathrm{FV}$ in the area where the periosteum and bone tissue contact had significant changes (Fig. 4D).

\section{The analyses of osteon level in macro-mesoscopic FE model}

Some points were selected at the internal wall, the middle, the external wall, and the interstitial bone in Region 1-Region 8 (Fig. 1e, f) to analyze and compared the response of FP and FV, respectively. The peak values of Region 2-Region 7 have no significant difference; however, the peak values of Region 1 and Region 8 were significantly smaller than other regions. The peak FP decreases gradually from interstitial bone to the inner wall of osteon (Fig. 5A). The FV at the inner wall of osteon had the maximum value, and the range of peak FV in osteon was about $5 \times 10^{-8} \mathrm{~m} / \mathrm{s}-8 \times 10^{-8} \mathrm{~m} / \mathrm{s}$ (Fig. $5 \mathrm{~B}$ ). The value of FV in both interstitial bone and outer wall of osteon was less than $2 \times 10^{-8} \mathrm{~m} / \mathrm{s}$ (Fig. 5B), which meant that the fluid stimulation generated by fluid flow in these locations was too small to cause the response of osteocyte's mechanoreceptors and was called "dead zone" [14].

The FP (Fig. 5C) and FV (Fig. 5D) of Osteon 2-7 showed the symmetrical distribution around the Haversian canal, but because of the influences of the boundary conditions, the FP and FV of Osteon 1 and Osteon 8 were asymmetric distribution. The FP and FV on the side near endosteum and periosteum both had a trend of decreasing markedly.

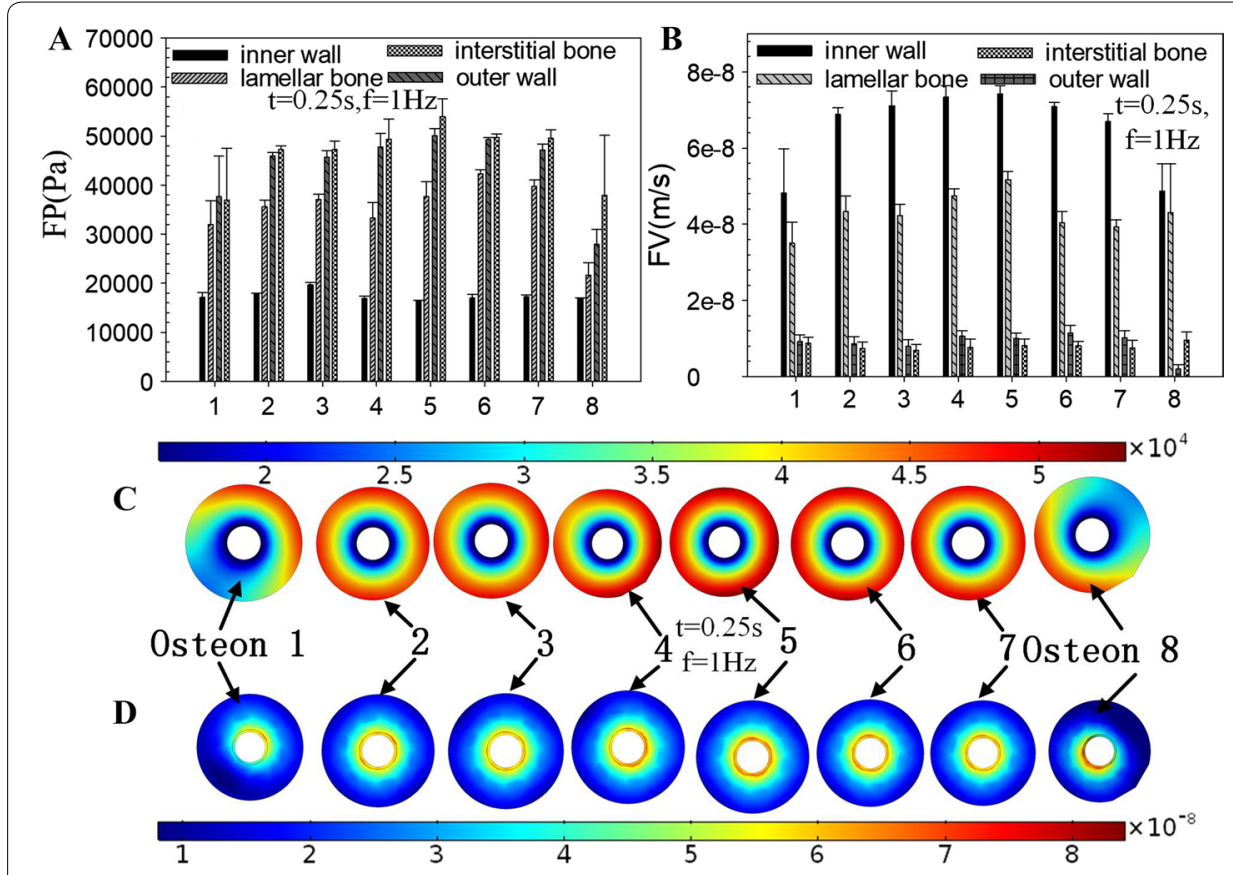

Fig. 5 Detailed analyses of the maximum response of FP $(\mathbf{A})$ and FV $(\mathbf{B})$ at different locations in Region $1-$ Region 8 (Fig. 1e). The distributions of FP (C) and FV (D) of Osteon 1-Osteon 8 (Fig. 1e) 


\section{Effects of Young's modulus $(E)$ and permeability $\left(\boldsymbol{k}_{\text {Icp }}\right)$ on mesoscale FE model}

As a verification, the VMP and FP states at the cuts where the mesoscale models had displacements and pressure prescribed by the results in the whole model (Fig. 1g) were checked. Such a comparison was shown in Fig. 6. For the range of parameters investigated, the computed peak VMS of the whole macro-mesoscopic models (Whole 1, 2, and 3 ) and mesoscale models (Case 1, 2, and 3) was about $2.6 \times 10^{7} \mathrm{~Pa}$ and $2.62 \times 10^{7} \mathrm{~Pa}$, respectively, and the peak value of FP was about $4.8 \times 10^{4} \mathrm{~Pa}$ and $4.7 \times 10^{4} \mathrm{~Pa}$, respectively. The peak values of VMS and FP for the whole models were about $0.1 \% \sim 1 \%$ and $1 \% \sim 2 \%$ different compared to that in the mesoscale models, which were expected given the coarse mesh in the whole model. The results strongly indicate that the mesoscale models had been set up correctly. The cut through the whole models (Whole 1, 2, and 3 ) in Fig. 6 displayed that the stresses and pressures were not well resolved. The stress and pressure fields are not smooth, especially around Haversian canal. Due to the large size span of the whole model, sometimes it is not feasible to have a mesh that at the same time captures the global behavior and resolves the detail structures with high accuracy. For thin bone lamella structures, it is common that the regions with different properties are small. The mesoscale models can simulate the detail structures more accurately. In

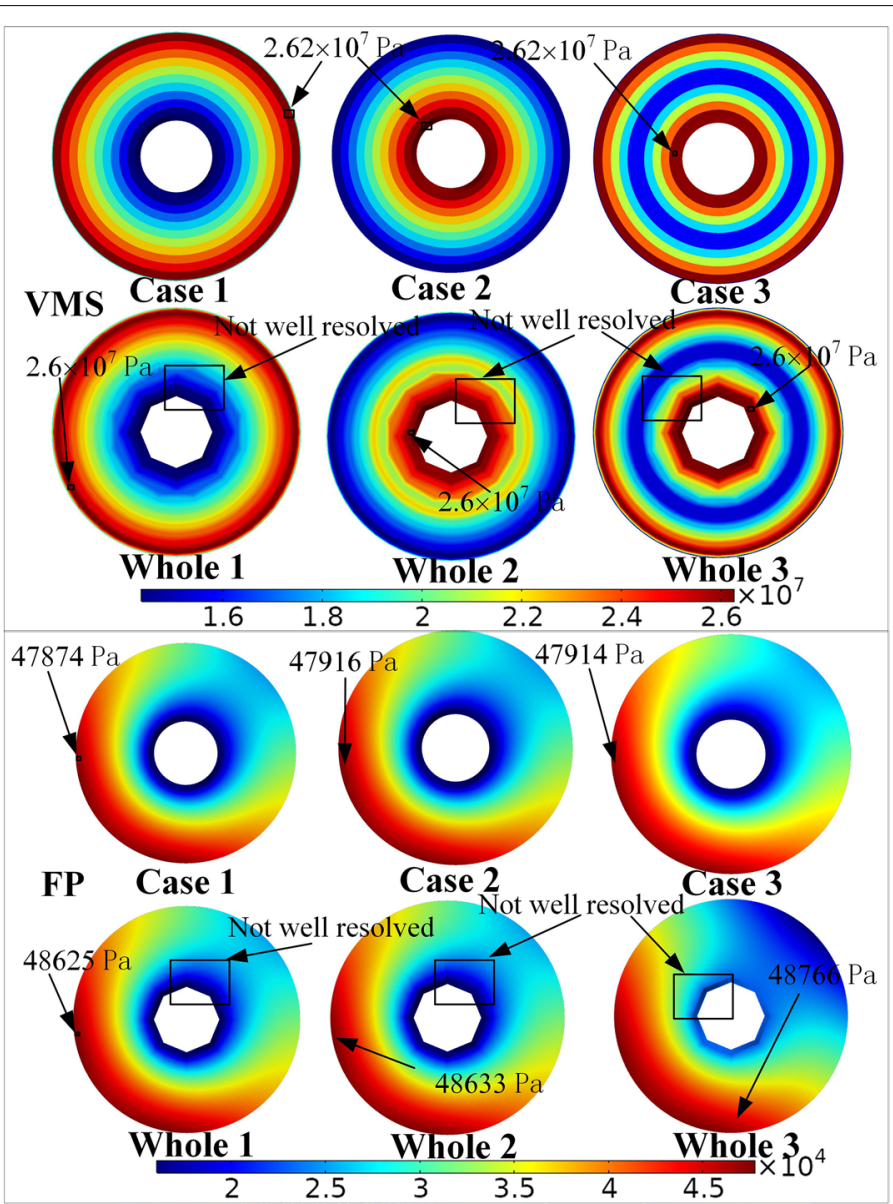

Fig. 6 The distributions of maximum VMS and FP over the selected osteon. The whole model (Whole 1, 2, and 3 ) and the mesoscale models (Cases 1,2, and 3) are compared 

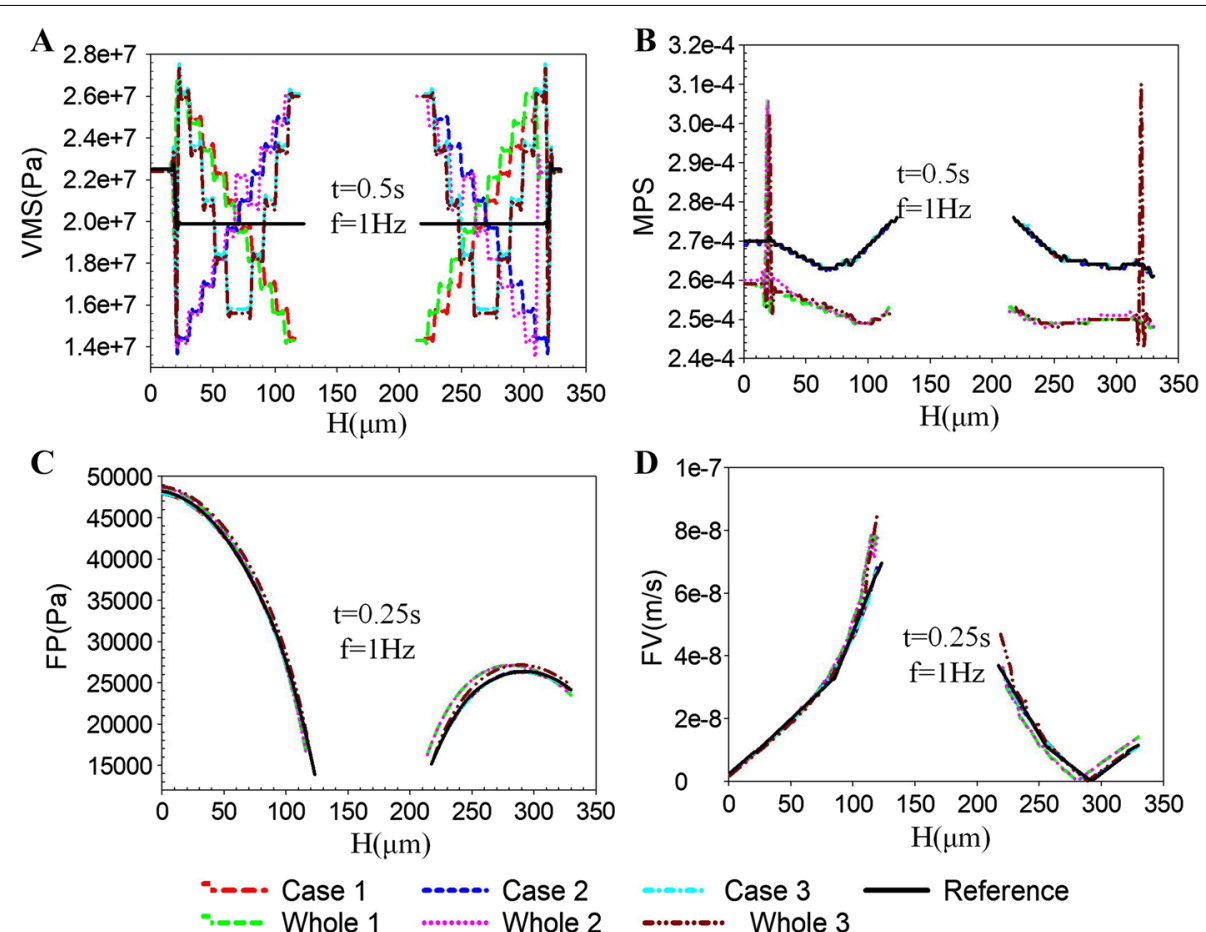

Fig. 7 Effects of different $E$ in each osteon lamella on mesoscale model. The maximum responses of VMS (A), MPS (B), FP (C), and FV (D) along the line $\mathrm{H}$ for the whole models (Whole 1, 2, and 3) and the mesoscale models (Cases 1, 2, and 3)

the corresponding figures from the mesoscale models, Case 1, Case 2, and Case 3, the stress and pressure field were smooth and well resolved. The finer mesh in the mesoscale models was better than the coarser mesh of the whole models in capturing the changes of VMP, MPS, FP, and FV. It was, however, observed in real physiological environment that a thin layer was required. If the bone lamellae were to be created in all osteons of the whole model, the simulation would require large computational resources. A Free Tetrahedral mesh was used. The whole model with mesoscopic structure (which is only in the selected osteon) consists of 58,180 elements and the mesoscale model consists of 33,256 elements. To better resolve details with the mesh, we set maximum element size $500 \mu \mathrm{m}$, minimum element size $5 \mu \mathrm{m}$, curvature factor 1.5 , resolution of narrow regions 0.6 and maximum element growth rate 0.5 in the whole model, and set maximum element size $27.5 \mu \mathrm{m}$, minimum element size $2 \mu \mathrm{m}$, curvature factor 1.4, resolution of narrow regions 0.4 and maximum element growth rate 0.7 in the mesoscale model. In the current example, the whole model consisted of about 1,101,293 degree of freedoms while the mesoscale models consisted of 245,221 degree of freedoms.

In order to investigate the effect of the $E$ and $k_{\text {lcp }}$ of different osteon lamellae on its poroelastic mechanical behavior, a line segment $\mathrm{H}$ (Fig. 1h) was selected along the radius direction of the bone tissue passing through the mesoscale model, and the changes of VMS, MPS, FP, and FV on H were observed. The difference between the VMP, MPS, FP, and FV of the whole models and of the mesoscale models was small. The $E$ had significantly effect on the VMP (Fig. 7A), MPS (Fig. 7A), FP (Fig. 7A), and FV (Fig. 7A). 

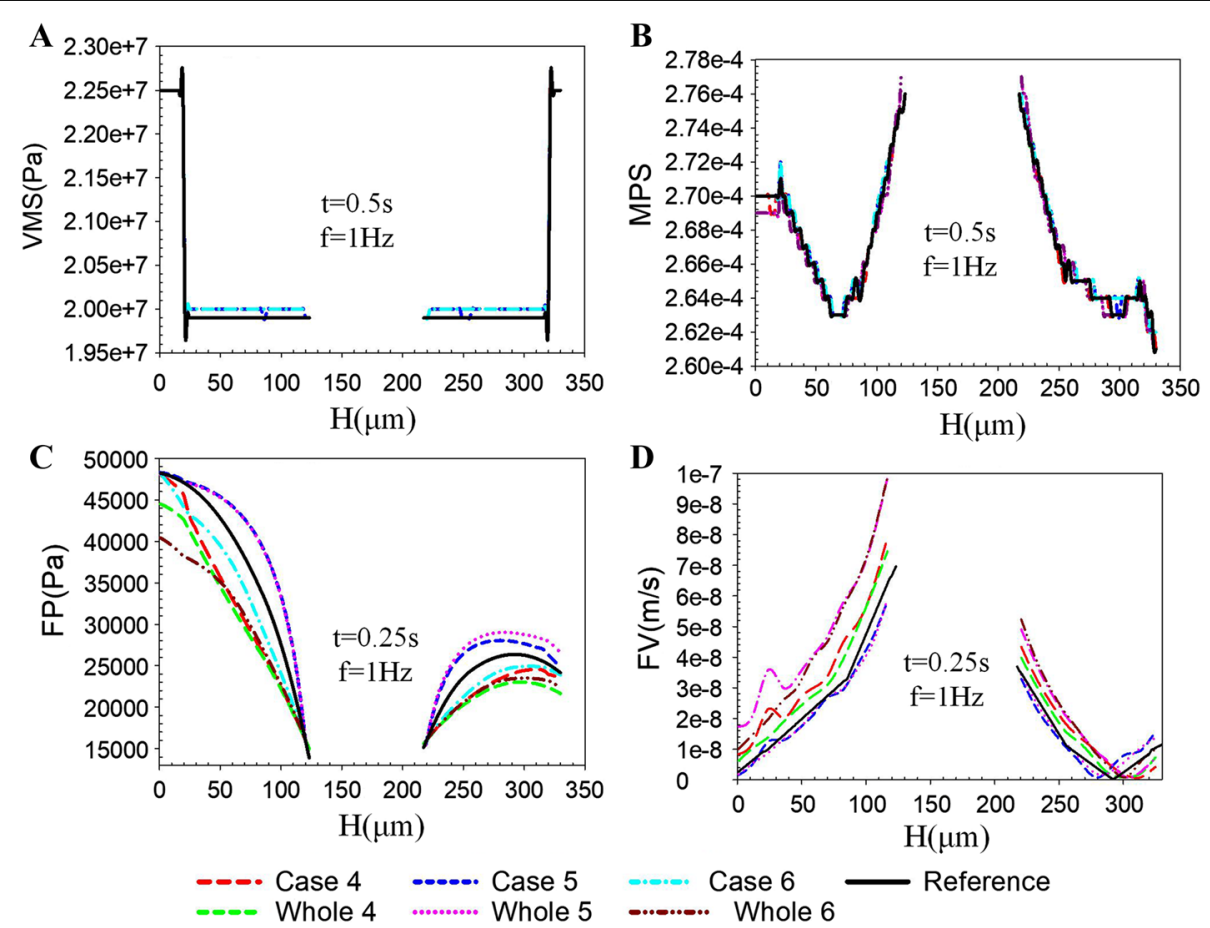

Fig. 8 Effects of different $k_{\text {lcp }}$ in each osteon lamella on mesoscale model. The maximum responses of VMS $(\mathbf{A}), \operatorname{MPS}(\mathbf{B}), \mathrm{FP}(\mathbf{C})$, and FV (D) along the line $\mathrm{H}$ for the whole models (Whole 4, 5, and 6) and the mesoscale models (Cases 4, 5, and 6)

With the different $E$ of each osteon lamella, the VMS of the bone lamella showed gradient change (Fig. 7A). As shown in Fig. 7B, the local MPS at medial lamellae position increased obviously in three cases, and the local MPS in Case 1 was significantly larger than Case 2 and Case 3. As shown in Fig. 7A, B, the peak VMS in Case 1 was at lateral lamellae, while the peak VMS occurred at medial lamellae in Case 2 and Case 3.

Figure 8 shows that the $k_{\text {lcp }}$ had significantly effect on the FP (Fig. 8C) and FV (Fig. 8D) of osteon lamellae, but had a little impact on the VMS (Fig. 8A) and MPS (Fig. 8B). As shown in Fig. 8D, due to the low permeability of the interstitial bone and cement line, the FV had an increasing trend in the junction of the cement line and osteon than the reference.

\section{Discussion}

This paper presented a multiscale poroelastic FE model under axial compressive cyclic loading to analyze the stress and strain field and fluid flow of bone. The distributions of the VMS, MPS, FP, and FV in endosteum, interstitial bone, osteon, and periosteum were analyzed on macro-mesoscopic model, and the effects of $E$ and $k_{\text {lcp }}$ on stress and strain field and fluid flow in mesoscopic model were investigated.

The osteogenic function of periosteum is more important than the bone marrow and endosteum, and the periosteum has abundant pluripotent stem cells and molecular factors of regulating cell behavior play an important role in providing cells resource for bone repairing and bone healing $[15,16]$. The material properties of periosteum selected in our model, which was considered to have abundant osteoprogenitor cells 
[17], made it more compliant. This had important effects as periosteum deform elastically at small strains. As shown in Fig. 4B, the MPS on the periosteum and endosteum was much larger than the interstitial bone and osteon, which results in a large strain gradient that may lead to greater strain stimulation on the bone cells on the endosteum and periosteum. However, the use of a transversely isotropic model for the periosteum and endosteum with a small elastic modulus of 4.41 $\mathrm{MPa}$ in radial direction and 25.67 MPa in axial direction resulted in a much lower VMS (Fig. 4A). The large VMS (Fig. 4A) in interstitial bone makes it easy to produce crack and fatigue damage, and the properties of high VMS and crack-prone of interstitial bone can provide a protection to the osteon, which helped to protect the osteocyte and maintained normal metabolic activity in the bone. This result was reasonable in the functions of maintaining structural integrity and resistance to fatigue damage in the process of biology evolution.

The maximum FP and FV of the whole bone tissue tend to be in a distribution of great in the middle and small at both ends (Fig. 5). The higher the FP and FV in osteon, the stronger the fluid stimulation is perceived by the osteocytes, which may lead to the physiological activities such as bone remodeling and bone metabolism more active. The distributions of FP and FV of Osteon 2-7 in Fig. 5 had little difference, which suggested that the fluid stimulation that the osteocytes felt in these osteons was basically the same. However, the asymmetrical distributions of FP and FV in Osteon 1 and Osteon 8 were found. The difference of FP and FV in Osteon 1, Osteon 8, and Osteon 2-7 may lead to different mechanosensation in osteocytes. The difference may relate to endosteum and periosteum. Studies had shown that the endosteum and the periosteum had important material exchange and signal transduction with bone tissue [18]. The periosteum and endosteum are closely related to the activities of bone formation and bone resorption, which together maintain the stability of the thickness of cortical bone [19]. The FV at the inner wall of the osteons was much larger than other positions, with a peak value about $8 \times 10^{-8} \mathrm{~m} / \mathrm{s}$ (Fig. $5 \mathrm{~B}$ ). The maximum FV in both interstitial bone and outer wall of osteon was less than $2 \times 10^{-8} \mathrm{~m} / \mathrm{s}$ (Fig. 5B), which means that the fluid stimulation generated by fluid flow in these locations was too small to cause the response of osteocyte's mechanoreceptors and was called "dead zone" [14].

The variations of $E$ in 3 cases in the mesoscale model are all derived from the experimental observations [20-23]. As shown in Fig. 6, there were obvious high stress at the medial lamella in Case 2 and Case 3. High stress can lead to initiation of cracking by fatigue. Therefore, it is easy to appear microcrack damage near the Haversian canals in Case 2 and Case 3. Under physiological load, the bone formation of osteoblasts interacted with bone resorption of osteoclasts to complete the growth of new bone and the removing of old bone, and therefore, there would be more new bone formations in the large stress region to form strong bone lamellae. According to the geometry of osteon, the redistribution of stress in the existing structure will be hindered by Haversian canal, which should lead to the presence of stress concentration. The existence of stress concentration around the Haversian canal will lead to the increase of $E$ (Case 2 and Case 3), which conformed to principle of bone adaptability. In Case 1 (Fig. 6), the lateral bone lamellae had higher stress and medial bone lamellae had lower stress, and the high stress 
region of lateral bone lamellae could cause stress shielding to medial bone lamellae. This stress shielding effect can prevent the stress concentration around Haversian canal to damage the osteon and provide protection to osteon [24]. Therefore, the results in Case 1 also conformed to the functions of maintaining structural integrity and resistance to fatigue damage in biological evolution. As shown in Fig. 7C, D, the different distributions of $E$ had influence on the FP and FV, which indicated that the variations of $E$ had effect on the fluid flow of osteon. The microcracks could affect the fluid flow behaviors of osteon [25]. The osteocytes around the Haversian canal could feel larger fluid stimulation (Figs. 5B, 7D and 8D), which may be related to the high stress around the Haversian canal and the susceptibility to initiation of microcracks. The existence of stress concentration and microcracks could make the bone formation more frequent to increase the strength of bone lamellae and repair microcracks.

Permeability can be regarded as a macro-index to describe the microscopic flow behavior in bone tissue [26, 27]. According to previous theoretical and experimental results, the range of $k_{\text {lcp }}$ was $10^{-17} \mathrm{~m}^{2}$ to $10^{-25} \mathrm{~m}^{2}$ [28]. The variations of $k_{\text {lcp }}$ in bone lamellae might be related to the distribution of the bone canaliculi and lacuna, the low-permeability regions might have less bone canaliculi and lacuna [29]. Although researchers had done extensive research on the permeability of bone, the effect of gradient distribution of permeability of osteon lamellae on the biological responses of osteocyte under fluid flow was still unclear. Our study found that the heterogeneous distribution of permeability in osteon lamella had a significant effect on FP and FV (Fig. 8). The FV was found to fluctuate at bone lamellae and cement line that was different from the findings of [10, 26]. In reality, the micropore of bone tissue may pass through the cement line [30], so the cement line may be permeable. Although the permeability value of the cement line is still unclear, this permeability of the cement line may change the mechanical behavior of cortical tissue. Therefore, we propose that the osteon in the ideal model is covered by a cement line. In addition, because the permeability of the cement line is lower than that of the osteon, the flow velocity at the cement line increases obviously, which will increase the fluid stimulation of the osteocytes near the outer wall of osteon. This mesoscale model was investigated by multiscale method, and the boundary conditions were more approach to real mechanical environment.

This paper established multiscale FE model to study strain and stress distributions and the fluid flow based on the poroelastic theory and provided a foundation for further exploration of the micromechanism of the growth and differentiation of osteocyte. Furthermore, we were restricted to simplified finite element models, whereas the bone tissue has more complex geometric structure, boundary conditions, and physiological load conditions. Incorporation of a more realistic model of bone tissue would prove useful for a more accurate representation of the different responses of stress and strain distribution and fluid flow when under physiological load. Future refinements of the model will address the inherent limitations. Nevertheless, this study represented a significant step in developing a multiscale model of bone tissue that incorporated explicit representation of osteon lamellae and cement line parameters. The future work is to establish microscale model based on the multiscale method and further quantify the load and fluid flow signal transfer from macroscale and mesoscale to microscale. 


\section{Conclusions}

In summary, a multiscale poroelastic finite element method for the hierarchical structure of bone tissue was developed under axial compressive cyclic load, and the distribution of stress and strain and fluid flow in bone were investigated in different scales. Multiscale method can reflect the real physiological environment of different layers more accurately than research each component of bone separately. The further model can be used to analyze the effect of bone scaffold, bone substitute or implants on the stress and fluid flow distributions of bone tissue to more accurately assess the potential beneficial and harmful effects, so as to accurately achieve better individual matching. This work provides a better understanding of fluid flow and mechanotransduction in bone remodeling.

\section{Methods}

\section{Governing equations for poroelastic bone model}

Poroelasticity was first developed by Biot and widely used in solid-liquid coupling poroelastic materials [31]. The following governing equations can be used to describe the poroelastic behavior of bone, and no body forces are taken into account [14, 26]. Constitutive laws for the solid matrix material and the saturating fluid can be written as:

$$
\begin{aligned}
& \boldsymbol{\sigma}=\mathbf{M} \varepsilon-\alpha p \\
& p=M[\xi-\operatorname{tr}(\alpha \varepsilon)]
\end{aligned}
$$

where $\boldsymbol{\sigma}$ is the total stress tensor, $\mathbf{M}$ is the stiffness tensor of the drained porous matrix, $\varepsilon$ is the total strain tensor, $\alpha$ is the Biot's tensor, $\mathrm{p}$ is the pore pressure, $M$ is the Biot's modulus, $\xi$ is the variations in fluid content, and $\operatorname{tr}()$ is the trace operator.

The equilibrium equation:

$$
\rho \ddot{\mathbf{u}}^{s}-\nabla \cdot \boldsymbol{\sigma}=\mathbf{0}
$$

here, the total density $\rho$ is related to the porosity $\phi$, the density of solid phase $\rho_{\mathrm{S}}$, and the density of fluid phase $\rho_{\mathrm{f}}$, and the $\rho$ can be defined by relation $\rho=\phi \rho_{\mathrm{f}}+(1-\phi) \rho_{\mathrm{s}}$, and $\ddot{\mathbf{u}}^{s}$ is the second derivative of the displacement.

Fluid mass conservation equation:

$$
\frac{\partial \xi}{\partial t}=-\nabla \cdot \mathbf{V}
$$

Darcy's law:

$$
\mathbf{V}=-\mathbf{k}\left(\nabla p+\rho_{\mathrm{f}} \ddot{\mathbf{u}}^{s}\right)
$$

here, $\mathbf{V}$ is the velocity vector and $\mathbf{k}$ is the intrinsic permeability tensor which can be defined by the relation $\mathbf{K}=\mathbf{k} / u$, where $\mathbf{K}$ is the permeability tensor and $u$ is the dynamic viscosity of interstitial fluid.

Inertia items in Eq. (3) and (5) can be ignored, because the bone is always subjected to low frequency cyclic loading in daily life and it has little effect on computing results. The simplified governing Eq. (6) is obtained by plugging (1) into (3) and plugging (2) and (5) into (4): 


$$
\left.\begin{array}{l}
\alpha \nabla p=\nabla \cdot(\mathbf{M} \varepsilon) \\
\frac{1}{M} \frac{\partial}{\partial t} p-\nabla \cdot(\mathbf{k} \nabla p)=-\frac{\partial}{\partial t}[\operatorname{tr}(\alpha \varepsilon)]
\end{array}\right\}
$$

\section{Establishment of macroscale poroelastic mathematical model and FE model}

In macroscale model, we neglected the bone marrow cavity and trabecular bone and established a hollow bone model in the cylindrical coordinate system $(r, \phi, z)$. As shown in Fig. 1A, $a, b$, and $h$ represent inner radius, outer radius, and height, respectively. The surface of periosteum was set no-flow conditions [32]. Equation (7), reported by literature [33, 34], models a modified physiological arterial pressure pulse (in $\mathrm{mmHg}$ ) as the hydrostatic pressure for the surface of endosteum.

$$
P_{0}=80+\frac{120-80}{2} \times\left\{\begin{array}{l}
0.5+0.5 \cos (10 \pi(t-0.1)), 0<t \leq 0.1 \\
1.5-0.5 \cos (10 \pi(t-0.5)), 0.1<t \leq 0.3 \\
0.5+0.5 \cos (5 / 3 \pi(\mathrm{t}-0.3)), 0.3<t \leq 0.9
\end{array}\right\}
$$

The cyclic loads were axial to represent longitudinal compression on the top and bottom surface $[32,35]$. The solution of fluid pressure can be obtained:

$$
p(r, t)=\frac{\frac{M E_{r}\left(E_{z}-E_{r} v_{z}^{2}\right)}{\left(1+v_{r}\right)\left(E_{z}-E_{z} v_{r}-2 E_{r} v_{z}^{2}\right)}\left(\alpha c+\alpha \varepsilon_{z 0}\right)}{\frac{E_{\mathrm{r}}\left(E_{z}-E_{r} v_{z}^{2}\right)}{\left(1+v_{r}\right)\left(E_{z}-E_{z} v_{r}-2 E_{r} v_{z}^{2}\right)}+M \alpha^{2}} \times\left[\frac{I_{0}(C r) K_{1}(C b)+K_{0}(C r) I_{1}(C b)}{I_{0}(C a) K_{1}(C b)+I_{1}(C b) K_{0}(C a)}-1\right] e^{i \omega t}
$$

where $I_{n}$ and $K_{n}$ represent the first kind and the second kind modified Bessel function of order $n(n=0,1)$, respectively. $\varepsilon_{z 0}$ is amplitude of axial strain, $E$ is drained Young's modulus $(\mathrm{Pa})$, and $v$ is Poisson's ratio of the drained porous matrix. $\alpha$ is the Biot-Willis coefficient, and c represents the integral constant determined by the boundary conditions. The $E_{r}, v_{r}$ and $E_{z}, v_{z}$ represent radial and axial drained Young's modulus and Poisson's ratio, respectively. The constant $C$ can be determined by the relation:

$$
C=\sqrt{i \omega \mu\left(\frac{E_{\mathrm{r}}\left(E_{z}-E_{r} v_{z}^{2}\right)}{\left(1+v_{r}\right)\left(E_{z}-E_{z} v_{r}-2 E_{r} v_{z}^{2}\right)}+M \alpha^{2}\right) / \frac{k M E_{\mathrm{r}}\left(E_{z}-E_{r} v_{z}^{2}\right)}{\left(1+v_{r}\right)\left(E_{z}-E_{z} v_{r}-2 E_{r} v_{z}^{2}\right)}}
$$

where $i=\sqrt{-1}, \omega$ represents load frequency, and $k$ is intrinsic permeability.The fluid velocity $V$ can be given by Darcy's Law:

$$
\mathrm{V}=-\frac{k}{\mu} \frac{\partial p}{\partial r}
$$

In order to provide the basis for researching the stress and strain field and fluid flow in various functional units by poroelastic FE method, the validity of poroelastic FE model was validated by comparing numerical result with simulation results. The analytical solution was obtained by MATLAB software. The poroelastic FE model was established by COMSOL Multiphysics. To simulate the mechanical environment of bone tissue, the load-displacement $w$ of $z$ direction was axial to represent longitudinal compression on 
the top and bottom surface. The amplitude of harmonic displacement $(w)$ and frequency $(f)$ is $0.5 \mu \mathrm{m}$ and $1 \mathrm{~Hz}$, respectively. The maximum axial strain $(\varepsilon)$ is $1000 \mu \varepsilon$ in a cycle:

$$
w=A[\cos (2 \pi f t)-1][\mathrm{mm}]
$$

There are two kinds of porosities associated with bone fluid: the vascular porosity (order $20 \mu \mathrm{m}$ ) and the lacunar-canalicular porosity (order $0.1 \mu \mathrm{m}$ ). The range of permeability $\left(k_{\mathrm{vp}}\right.$ and $\left.k_{\mathrm{lcp}}\right)$ that describes the fluid flow in the vascular porosity $\left(\phi_{\mathrm{v}}\right)$ and the lacunar-canalicular porosity $\left(\phi_{\mathrm{lc}}\right)$ are $10^{-13} \mathrm{~m}^{2}-10^{-17} \mathrm{~m}^{2}$ and $10^{-17} \mathrm{~m}^{2}-10^{-25} \mathrm{~m}^{2}$, respectively [28]. We set $k_{\mathrm{vp}}=10^{-15} \mathrm{~m}^{2}$ and porosity $\phi_{\mathrm{v}}=0.04$ to describe fluid flow in the vascular porosity and $k_{\mathrm{lcp}}=10^{-19} \mathrm{~m}^{2}$ and porosity $\phi_{\mathrm{lc}}=0.05$ to describe fluid flow in the lacunar-canalicular porosity. Croker et al. found that the cross-sectional diameter and thickness of cortical bone of human femur $(22.1-32.8 \mathrm{~mm})$ were thicker than animals by analysis and comparison of human, sheep, and kangaroos using statistical methods [36]. In order to simplify calculation and facilitate comparison of the upcoming animal experiment, the cross-sectional diameter and the height of segment bone are set $1 \mathrm{~cm}$ and $1 \mathrm{~mm}$, respectively. The related parameters are shown in Table 1 [14, 27, 37].

\section{Macro-mesoscopic FE model}

\section{Establishment of macro-mesoscopic FE model}

It is difficult to study the relationship of fluid flow within different levels and functional units by experimental and theoretical methods; therefore, the FE simulation method becomes the first choice. As shown in Fig. 1B, the macro-mesoscopic model considered the endosteum, osteon, interstitial bone, and periosteum, but the Haversian canal and the marrow cavity in bone were neglected (Fig. 1C). As shown in Fig. 1d, due to symmetry, only $1 / 8$ model was observed in the computations. The radius of osteon was set $R_{\mathrm{o}}=150 \mu \mathrm{m}$, and the Haversian canal radius is set $r_{\mathrm{o}}=50 \mu \mathrm{m}$. The periosteum is a strong connective tissue envelope covering the bone surface except joints. It was tightly bound to the outer wall of bone tissue, and the thickness was set $150 \mu \mathrm{m}$ [38]. The endosteum was a thin connective tissue envelope covering the bone marrow cavity and bone trabecula, and the thickness was set $50 \mu \mathrm{m}$.

\section{Boundary conditions and material parameters}

The surface of periosteum and bone marrow were set to the same value as the macroscopic model. The FP of Haversian canal was always ignored in previous study [10, 14, 27]; however, the span of both $k_{\mathrm{vp}}$ and $k_{\mathrm{lcp}}$ was very large [28], and when the gap of permeability value between $k_{\mathrm{vp}}$ and $k_{\mathrm{lcp}}$ was not that big, the FP of Haversian canal couldn't be ignored. In macro-mesoscopic model, the FP of Haversian canal was derived from the calculation results of the corresponding locations of macroscale model. The loaddisplacement is the same as macroscale model.

Due to the symmetry of full model, the both sides and bottom surface of the segment 1/8 model which cut from the whole model applied constrained symmetrically to prevent rigid body motion. Because the endosteum, osteon, and interstitial bone and periosteum were tightly bound together, all geometric objects were tied together by using the function of Form Union in COMSOL Multiphysics software to make the condition of the mesh border lines continuous. 
The Young's modulus $(E)$ of interstitial bone was 10\% larger than osteon, and the Poisson ratio $(v)$ was $10 \%$ smaller than osteon [39]. The transverse isotropic elastic constants for cortical bone were used. McBride et al. measured that the axial and radial elastic modulus of periosteum were 18.8-32.5 MPa and 3.19-5.62 MPa [40], respectively, and the average values 25.65 MPa and 4.41 MPa were used in this model. The Poisson's ratio was 0.49 [19]. The permeability of the periosteum from the bone to muscle surface of periosteum and the muscle to bone surface of the periosteum was much different, and we only considered the permeability $\left(2.7 \times 10^{-16} \mathrm{~m}^{2}\right)$ between the periosteum and the bone tissue [41]. For other poroelastic material parameters, we set the same value on macroscopic and macro-mesoscopic model. The material parameters used in the FE model are shown in Table $2[14,19,37,40,41]$.

Different precision of meshes were studied, to demonstrate that the results were converged with respect to mesh refinement-any further refinement of the mesh would only marginally improve the precision of the results. A Free Tetrahedral mesh was used and included 48,375 elements.

\section{Mesoscopic FE model}

\section{Establishment of FE mesoscale model including macro-meso interface}

The establishment of mesoscale model consisted of two steps. Firstly, the macroscopic and macro-mesoscopic models were analyzed in order to capture the general trends and to identify the critical part. Secondly, a fine mesoscale model containing the critical part was made, and the study was resolved. In order to allow for smooth transition between macroscale and mesoscale, the FE mesoscopic model including macro-meso interface was established (Fig. 1g). The change of material parameters was consistent with the mesoscale model.

\section{Establishment of mesoscopic FE model}

The osteon was a basic unit for organizing and constructing the cortical bone, which composes of multilayered quasi-cylindrical composites of compact tissue arranged in 7-10- $\mu$ m-thick lamella around the Haversian canal (Fig. 1i) [20]. Each osteon lamella had different properties [26]. Each osteon was encircled in a 1-5- $\mu$ m-thick interface structure form, which was called the cement line, to separate osteon from interstitial bone (Fig. 1j). In the analysis, 10 bone lamellae were established. The cement line was set $1 \mu \mathrm{m}$ [42]. The global effects from the macroscale model were transferred to the mesoscale model via appropriate boundary conditions. By the analysis of the simulation results of macroscale model, we confirmed the critical part near the outer region of periosteum as the position of mesoscale model. As shown in Fig. 1h, the mesoscale model was a cube $(340 \mu \mathrm{m})$ that cut from the macro-mesoscopic model near the periosteum, which contained one osteon.

\section{Boundary conditions and material parameters of the mesoscale model}

The mesoscale model was based on the coupling of Structural Materials Module and Darcy's law in COMSOL Multiphysics. Since the model contained the properties of structural mechanics and fluid flow behaviors that were modeled with a poroelastic material, many degrees of freedom were required in order to obtain the accurate 
behaviors of poroelastic mechanics in all functional units. The concept of this technique required that an analysis of the macro-mesoscopic model was performed in order to capture general trends, followed by an analysis of a mesoscale model which the macromesoscopic structure units subdivided into mesoscale structure units were studied in detail. The result of the macro-mesoscale, the displacement and pore pressure, were prescribed directly to the boundaries where the mesoscale model was cut out of the macro-mesoscale and via strain and pressure gradient transfer to the mesoscale model, which ensured the continuity of the two scales.

Each lamella was given different value of $E$ and $k_{\mathrm{lcp}} . E_{r} 1$, and $E_{z} 1$ represent the radial and the longitudinal Young's modulus of lamella 1 (Fig. 1i), respectively, $E_{r} 2$, and $E_{z} 2$ represent the radial and the longitudinal Young's modulus of lamella 2 (Fig. 1i), respectively, and so on. Generally speaking, the distribution of $E$ along radial direction could be divided into the following three cases: Case 1: The value was high in the middle bone lamellae and low in lateral and medial bone lamellae [20]. Case 2: There was an increasing trend of $E$ from the medial to the lateral [21]. Case 3: There was a decreasing trend of $E$ from the medial to the lateral $[22,23]$.

As same as Chen et al., we assumed the osteon lamellae were all perfectly bonded, and each lamella had different permeability [10]. $k_{\mathrm{lcp}} 1$ represents the lacunar-canalicular permeability of lamellae 1 (Fig. 1i), and $k_{\text {lcp }} 2$ represents the lacunar-canalicular permeability of lamellae 2 , and so on. Three cases of permeability were considered in this model. In Case $4, k_{\text {lcp }}$ decreased linearly from lamella 1 to lamella 10 . In Case $5, k_{\text {lcp }}$ increased linearly from lamella 1 to lamella 10 , and in Case 6, the $k_{\mathrm{lcp}}$ had a symmetric distribution. The reference model was the macro-mesoscopic model which $E$ and $k_{\mathrm{lcp}}$ were a fixed value at the corresponding position. The specific parameters of $E$ and $k_{\mathrm{lcp}}$ in each lamella were shown in Tables 3 and 4.

\section{Abbreviations}

FP: fluid pressure; FV: fluid velocity; VMS: von Mises stress; MPS: maximum principal strain; $E$ : Young's modulus; $k_{\mathrm{lcp}}$ : lacunar-canalicular permeability; $k_{\mathrm{vp}}$ : vascular permeability; $\phi_{\mathrm{v}}$ : lacunar-canalicular porosity; $\phi_{\mathrm{lc}}$ : lacunar-canalicular porosity.

\section{Acknowledgements}

This work was supported by the National Natural Science Foundation of China (Nos. 11632013, 11702183, 11402162, 11572213, 11972242), Natural Science Foundation of Shanxi (No. 2016021145), and the Scientific and Technological Innovation Projects of Colleges and Universities in Shanxi Province (No. 2017135).

\section{Authors' contributions}

All authors have made substantial contributions to the conception of the methodology. All authors read and approved the final manuscript.

\section{Funding}

This study was funded by National Natural Science Foundation of China (Nos. 11632013, 11702183, 11402162, 11572213, 11972242), Natural Science Foundation of Shanxi (No. 2016021145), and the Scientific and Technological Innovation Projects of Colleges and Universities in Shanxi Province (No. 2017135).

Availability of data and materials

Data are available from the corresponding author upon reasonable request.

Ethics approval and consent to participate

Not applicable.

Consent for publication

Not applicable.

Competing interests

The authors declare that they have no competing interests. 


\begin{abstract}
Author details
${ }^{1}$ College of Biomedical Engineering, Shanxi Key Lab. of Material Strength, College of Biomedical Engineering \& Structural Impact, Taiyuan University of Technology, Taiyuan 030024, Shanxi, China. ${ }^{2}$ Biological Science and Medical Engineering, Beihang University, Beijing, China. ${ }^{3}$ Orthopaedic Bioengineering Research Laboratory, Department of Biomedical Engineering, Stony Brook University, Stony Brook, NY, USA.
\end{abstract}

Received: 9 June 2019 Accepted: 10 December 2019

Published online: 23 December 2019

\title{
References
}

1. Rho JY, Kuhnspearing L, Zioupos P. Mechanical properties and the hierarchical structure of bone. Med Eng Phys. 1998;20(2):92.

2. Cowin SC. Bone poroelasticity. J Biomech. 1999;32(3):217-38.

3. Kwon YW, Clumpner BR. Multiscale modeling of human bone. Multiscale Multidiscip Model Exp Des. 2018;1(2):133-43.

4. Frost HM. From Wolff's Law to the mechanostat: a new "face" of physiology. J Orthop Sci. 1998;3(5):282-6.

5. Frost HM. Skeletal structural adaptations to mechanical usage (SATMU): 2. Redefining Wolff's law: the remodeling problem. Anat Rec. 1990;226(4):414-22.

6. Hedayati R, Hosseini-Toudeshky H, Sadighi M, Mohammadi-Aghdam M, Zadpoor AA. Multiscale modeling of fatigue crack propagation in additively manufactured porous biomaterials. Int J Fatigue. 2018;113:416-27.

7. Tiwari AK, Kumar N. Establishing the relationship between loading parameters and bone adaptation. Med Eng Phys. 2018;56:16-26.

8. Saikia E, Hassan CR, Qin YX. Simulation of phased array ultrasound propagation for fluid flow regulation in enhancement of bone adaptation. Acous Soc Am J. 2017;141(5):4015.

9. Tiwari AK, Prasad J. Computer modelling of bone's adaptation: the role of normal strain, shear strain and fluid flow. Biomech Model Mechanobiol. 2017;16(2):1-16.

10. Chen Y, Wang W, Ding S, Xu W, Chen Q, Xing L. A multi-layered poroelastic slab model under cyclic loading for a single osteon. Biomed Eng Online. 2018;17(1):97.

11. Rustom LE, Boudou T, Nemke BW, Yan L, Hoelzle DJ, Markel MD, Picart C, Johnson AJW. Multiscale porosity directs bone regeneration in biphasic calcium phosphate scaffolds. ACS Biomater Sci Eng. 2017;3(11):2768-78.

12. Ascenzi MG, Kawas NP, Lutz A, Kardas D, Nackenhorst U, Keyak JH. Individual-specific multi-scale finite element simulation of cortical bone of human proximal femur. J Comput Phys. 2013;244(244):298-311.

13. Pastrama MI, Scheiner S, Pivonka P, Hellmich C. A mathematical multiscale model of bone remodeling, accounting for pore space-specific mechanosensation. Bone. 2017;107:208-21.

14. Nguyen VH, Lemaire T, Naili S. Poroelastic behaviour of cortical bone under harmonic axial loading: a finite element study at the osteonal scale. Med Eng Phys. 2010;32(4):384-90.

15. Colnot C, Zhang $X$, Tate MLK. Current insights on the regenerative potential of the periosteum: molecular, cellular, and endogenous engineering approaches. J Orthop Res. 2012;30(12):1869-78.

16. Hayashi $\mathrm{O}$, Katsube $\mathrm{Y}$, Hirose $\mathrm{M}$, Ohgushi H, Ito H. Comparison of osteogenic ability of rat mesenchymal stem cells from bone marrow, periosteum, and adipose tissue. Calcif Tissue Int. 2008;82(3):238-47.

17. Uchida S, Doi Y, Kudo H, Furukawa H, Nakamura T, Fujimoto S. Transient expression of activin betaA mRNA on osteoprogenitor cells in rat bone regeneration after drill-hole injury. Bone. 2000;27(1):81-90.

18. Lai X, Price C, Xin L, Wang L. Imaging and quantifying solute transport across periosteum: implications for musclebone crosstalk. Bone. 2014;66(9):82-9.

19. Carpenter RD, Carter DR. Computational simulation of spontaneous bone straightening in growing children. Biomech Model Mechanobiol. 2010;9(3):317-28.

20. Raum K, Grimal Q, Gerisch A. Multiscale structure-functional modeling of lamellar bone. J Acoust Soc Am. 2010;127(3):2033.

21. Faingold A, Cohen SR, Wagner HD. Nanoindentation of osteonal bone lamellae. J Mech Behav Biomed Mater. 2012;9:198-206.

22. Ashman RB, Cowin SC, Buskirk WC, Van Rice JC. A continuous wave technique for the measurement of the elastic properties of cortical bone. J Biomech. 1984;17(5):349-61.

23. Faingold A, Cohen SR, Reznikov N, Wagner HD. Osteonal lamellae elementary units: lamellar microstructure, curvature and mechanical properties. Acta Biomater. 2013;9(4):5956-62.

24. Mayya A, Banerjee A, Rajesh R. Haversian microstructure in bovine femoral cortices: an adaptation for improved compressive strength. Mater Sci Eng C Mater. 2016;59:454.

25. Wu X, Wang Y, Wu X, Cen H, Guo Y, Chen W. Effects of microcracks on the poroelastic behaviors of a single osteon. Sci China Phys Mech Astron. 2014;57(11):2161-7.

26. Rémond A, Naïli S, Lemaire T. Interstitial fluid flow in the osteon with spatial gradients of mechanical properties: a finite element study. Biomech Model Mechanobiol. 2008;7(6):487-95.

27. Wu XG, Chen WY. A hollow osteon model for examining its poroelastic behaviors: mathematically modeling an osteon with different boundary cases. Eur J Mech. 2013;40(1):34-49.

28. Cardoso L, Fritton SP, Gailani G, Benalla M, Cowin SC. Advances in assessment of bone porosity, permeability and interstitial fluid flow. J Biomech. 2013;46(2):253-65.

29. Beno T, Yoon YJ, Cowin SC, Fritton SP. Estimation of bone permeability using accurate microstructural measurements. J Biomech. 2006;39(13):2378-87.

30. Curtis TA, Ashrafi SH, Weber DF. Canalicular communication in the cortices of human long bones. Anat Rec. 2010;212(4):336-44 
31. Biot MA. Theory of elasticity and consolidation for a porous anisotropic solid. J Appl Phys. 1955;26(2):182-5.

32. Fan L, Pei S, Lu XL, Wang L. A multiscale 3D finite element analysis of fluid/solute transport in mechanically loaded bone. Bone Res. 2016;4(3):16032.

33. Pfenniger A, Obrist D, Stahel A, Koch VM, Vogel R. Energy harvesting through arterial wall deformation: design considerations for a magneto-hydrodynamic generator. Med Biol Eng Comput. 2014;38(13):3325-38.

34. Umut Atakan G, Ozan A. The mechanical environment of bone marrow: a review. Ann Biomed Eng. 2008;36(12):1978-91.

35. Metzger TA, Niebur GL. Comparison of solid and fluid constitutive models of bone marrow during trabecular bone compression. J Biomech. 2016;49(14):3596-601.

36. Croker SL, Clement JG, Donlon D. A comparison of cortical bone thickness in the femoral midshaft of humans and two non-human mammals. Homo. 2009;60(6):551-65.

37. Smit TH, Huyghe JM, Cowin SC. Estimation of the poroelastic parameters of cortical bone. J Biomech. 2002;35(6):829-35.

38. O'Driscoll S, Saris D, Ito Y, Fitzimmons J. The chondrogenic potential of periosteum decreases with age. J Orthop Res. 2010;19(1):95-103.

39. Budyn É, Hoc T. Multiple scale modeling for cortical bone fracture in tension using X-FEM. Eur J Mech. 2007;16(2):213-36.

40. Mcbride SH, Evans SF, Tate ML. Anisotropic mechanical properties of ovine femoral periosteum and the effects of cryopreservation. J Biomech. 2011;44(10):1954-9.

41. Evans SF, Parent JB, Lasko CE, Xiaowen Z, Knothe UR, Thibault L, Tate ML. Periosteum, bone's "smart" bounding membrane, exhibits direction-dependent permeability. J Bone Miner Res. 2013;28(3):608-17.

42. Nobakhti S, Limbert G, Thurner PJ. Cement lines and interlamellar areas in compact bone as strain amplifiers - contributors to elasticity, fracture toughness and mechanotransduction. J Mech Behav Biomed Mater. 2014;29(6):235-51.

\section{Publisher's Note}

Springer Nature remains neutral with regard to jurisdictional claims in published maps and institutional affiliations.

- fast, convenient online submission

- thorough peer review by experienced researchers in your field

- rapid publication on acceptance

- support for research data, including large and complex data types

- gold Open Access which fosters wider collaboration and increased citations

- maximum visibility for your research: over 100M website views per year

At BMC, research is always in progress.

Learn more biomedcentral.com/submissions 